\title{
Correlation between Static Balance and Core Endurance among College Student with Forward Head Posture
}

\author{
Abhilash P.V ${ }^{1}$, Priya $S^{2}$, Mustafa K Kheriwala ${ }^{3}$ \\ ${ }^{1,2}$ Master of Physiotherapy (Musculoskeletal and Sports Physiotherapy), \\ Associate Professor, Laxmi Memorial College of Physiotherapy, Mangalore. \\ ${ }^{3}$ Post Graduate Student (Musculoskeletal and Sports Physiotherapy), Laxmi Memorial College of \\ Physiotherapy, Mangalore \\ Corresponding Author: Mustafa K Kheriwala
}

\begin{abstract}
Background: Proper posture is considered to be a state of musculoskeletal balance that involves a minimal amount of stress or strain to the body. When the head is held forward in relation to the trunk, the alignment is said to be poor and is referred as, 'forward head posture' (FHP). If abnormal posture persists for a long time, it compromises balance because of muscular imbalance which can cause loss of proprioception sense in joint and decreased balance, and trunk endurance is significantly reduced in FHP and may lead to poor muscular control of the spine.
\end{abstract}

\section{Purpose:}

To find the correlation between the core muscle endurance and balance among college student with forward head posture.

Methodology: A cross-sectional observational study was conducted in a tertiary care hospital. 25 healthy college student individuals within the age group of 18-30 years having forward head posture were taken. FHP was assessed by craniovertebral angle. Trunk endurance was measured by McGill core endurance test and static balance was assessed by standing stork test.

Results: Karl Pearson's correlation coefficient test was used to find the correlation between Trunk muscle endurance and static balance. Strong positive correlation was found which was statistically significant between trunk flexor endurance, trunk extensor endurance, right lateral endurance, left lateral endurance, and static balance.
Conclusion: Among college students with FHP decreased core endurance can affect the static balance.

Key words: forward head posture, core endurance, static balance.

\section{INTRODUCTION}

"Posture is usually defined as the relative arrangement of the parts of the body" . Posture is the orientation of anybody segment relative to gravitational vector $^{2}$. Good posture is that state of muscular and skeletal balance which protects die supporting structures of the body against injury and the minimal amount of stress-strain to the body ${ }^{1,3}$. Kendall described a standard for normal sagittal alignment involving theoretical straight line formed by reference points which are ear lobes, $7^{\text {th }}$ cervical vertebrae, acromion, greater trochanter, anterior to midline of the knee and slightly anterior to lateral malleolus". "Poor posture is a faulty relationship of various parts of the body which produce increased strain on the supporting structures and in which there is less efficient balance of the body over its base of support"1.

The head protrudes forward from sagittal plane and appears as front of the body ${ }^{4}$. Forward head posture leads to extension of atlanto occipital joint and upper cervical vertebrae as well as exaggerated 
anterior curve in the lower cervical vertebra and exaggerated posterior curve in upper thoracic vertebra to maintain balance ${ }^{5}$. This posture is also called "Scholar's neck", "Wearsie neck", "Reading neck" or "Turtle neck" $"$. FHP was identified by measuring craniovertebral angle. The normal CV angle is 49.9 degrees. Less than 49 degrees lead to FHP $^{7}$.

The muscle around the head, neck, and shoulder includes trapezius, sternocleidomastoid, suboccipital and temporal are affected by FHP and leads to persistent and abnormal pressure in muscle, fascia and nerves of neck and shoulder. It causes high load on superior trapezius and levator scapulae muscle ${ }^{4}$. FHP results in shortening of the neck extensors and elongation of the neck flexors and upper back erector spinae. If this abnormal posture persists for a long time, it leads to loss of normal forward flexion and muscle weakness, in addition, the persistence of FHP compromises balance because of muscular imbalance which can cause loss of proprioceptive sense in joint and decreased balance ${ }^{8}$.

"Balance refers to an individual ability to maintain their line of gravity within their base of support"9. FHP alters the center of gravity (COG) of the body that causes mechanical modifications related to postural control in torso and every other joint because of this the body tries to adapt these changes by altering its balance control mechanism. These adaptations decrease balance ability while performing activities and increases risk of fall and other musculoskeletal injuries ${ }^{4}$. Maintaining balance is coordinated by three systems. The first input is from the vestibular system. The second is the proprioceptive system originating from somatosensory receptors in muscles, tendons, and joints for kinesthetic sense, body posture and spatial awareness. Finally, the visual system sends visual signals about body's position ${ }^{10}$. When the body is at rest it is called static balance, and when the body is steady state motion then it's called dynamic balance ${ }^{11}$. A study done on FHP the Effects of forward head posture on static and dynamic balance control. They assessed the static and dynamic balance found that the static balance is more affected than dynamic balance ${ }^{4}$. There are various methods to check static balance clinically. The standing stork test is valid in assessing balance which was used in this study ${ }^{12}$.

The spine, pelvic girdle, abdominal, and proximal lower extremities are defined as part of the core of the body. The core is constructively a muscular box in which pelvic floor and hip girdle musculature as the bottom, the diaphragm is on the top, the abdominals in the anterior, and the paraspinal and gluteal muscles posterior. The strength of core muscle allows the system to stabilize the spine mechanically then distribute and deliver translation, compressive, and shear force to and from the rest of the body ${ }^{13}$. The core is the centrally placed, which provides linkage between upper and lower extremities function $^{14}$. A recent study done in 2020 to check trunk endurance in people with and without forward head posture suggests that trunk endurance is significantly reduced in FHP and may lead to poor muscular control of spine and may predispose people to pain and disability in the spinal segments ${ }^{15}$. Studies also suggest that core muscles play a vital role in maintaining balance, functional mobility, and postural stability ${ }^{16}$. A number of tests to check core endurance have been described. The participants in these study were assessed for their core endurance through McGill endurance tests $^{14,17}$.

There are various studies done which have compared the effects of FHP on balance and FHP on core endurance. As there is paucity in literature regarding the correlation of core endurance and static balance in FHP, the study has been undertaken. This study will further help in early intervention of core endurance and balance exercise in forward head posture. 


\section{METHODOLOGY \\ Design and setting}

A cross section observational study was conducted in a tertiary care hospital.

\section{Participants}

Twenty-five subjects with forward head posture fulfilling inclusion and exclusion criteria were recruited using convenience sampling technique. College students (18-30 yrs) both male and female who have craniovertebral angle less than 49 degrees were included. History of injury or trauma to cervical Spine, neck pain, congenital cervical Anomalies, Cervical spondylosis, Individuals undergoing medical or physiotherapy treatment for neck pain were excluded. All participants were verbally explained about the study in brief and then were recruited in the study after written consent.

\section{Procedure and Outcome measures}

Age, weight, height, and BMI were noted. Subjects perceived core endurance was assessed using McGill core endurance test and static balance was assessed using standing stork test. FHP was identified by measuring the Craniovertebral angle.

CVA: To measure the CVA, participants were imaged at a distance of $1.5 \mathrm{~m}$ from their sitting position, and the participant's shoulder and the camera height were placed at the same level (Moghadam et al., 2018). The CVA was measured using a horizontal line passing through the $\mathrm{C} 7$ spinous process and a line connecting $\mathrm{C} 7$ to the tragus of the ear. To measure the CVA, following procedure was conducted. A trained physiotherapist palpated C7 vertebra and attached a plastic pointer on. Pictures of participants' lateral view were taken using "ON PROTRACTOR" application via smartphone. CVA less than 49 degrees was considered as $\mathrm{FHP}^{18,19,20}$.

\section{Core endurance test}

All participants were given a demonstration of how to carry out the test correctly. A single trial was given for each test, to familiarize participants with the technique and procedure. A 3-4 min resting period was given between each core stability test to avoid fatigue. Participants were asked to hold a static position for as long as possible. Four tests which were using protocols established by McGill et al.

Trunk flexor endurance test: The participant was asked to lie in a crook-lying position with their trunk supported at 60 degrees of trunk flexion while hips and knees are at 90 degrees of flexion with arms crossed over the chest and feet on the plinth. The support of the trunk was removed and the participant was asked to hold the position as long as possible. If a participant was unable to do so; the timing was stopped and time was noted.

Trunk extensor endurance test: The participant was asked to lie in prone-lying position on plinth. Pelvis, hips, and knees were stabilized to the plinth by stabilization belts while a chair at the same height as the surface of table supported the trunk and upper extremitiess. Then, the participant was asked to hold a horizontal body position for as long as possible with arms crossed over the chest after the chair was removed. If a participant was unable to do so, the timing was stopped and time was noted.

Right and Left side bridge endurance test: The participant was asked to lie in sidelying position on the plinth or mat with a lower foot placed behind the upper one with knees extended. The participant held the torso off the plinth supported by the lower elbow and feet while lifting their hips off the plinth. They were asked to maintain the position as long as possible. Test was terminated when hips returned to plinth, timing was stopped and time was noted.

\section{Standing stork test}

The participant was made to stand comfortably on both feet with hands on the hip and instructed to lift one leg and place the toes of that foot against the knee of the other leg. The participant was then asked to raise the heel and stand on their toes on command. The stopwatch was started as the heel was raised from the floor. The 
stopwatch was stopped if the hands came off the hips or the supporting foot swiveled or moved in any direction, or the nonsupporting foot lost contact with the knee, or the heel of the supporting foot touched the floor. Every participant was made to perform three attempts for each leg and better result was recorded. The average of both legs was recorded for statistical analysis.

\section{Statistical analysis}

Descriptive statistics was used for demographic data such as age, weight, height, and BMI. Data were analyzed using SPSS v.26.0. Karl Pearson's correlation coefficient was used to find relation of core endurance with static balance. The ' $p$ ' value $\leq 0.001$ was considered as significant.

\section{RESULTS}

Twenty-five participants with Forward Head Posture were recruited for the study. All participants underwent core endurance tests (Trunk flexor test, Trunk extensor test, Right lateral flexor test, Left lateral flexor test), and Static balance test by using Standing stork test. (Table:1)

Table 1: Descriptive statistics

\begin{tabular}{|l|c|}
\hline \multicolumn{1}{|c|}{ Characteristics } & Mean \pm SD \\
\hline Age $($ years $)$ & $24.8 \pm 0.78$ \\
\hline BMI $\left(\mathrm{kg} / \mathrm{m}^{2}\right)$ & $24.1 \pm 3.3$ \\
\hline Trunk flexor endurance & $24.7 \pm 5.4$ \\
\hline Trunk extensor endurance & $15.8 \pm 4.8$ \\
\hline Right side bridge endurance & $19.4 \pm 4.6$ \\
\hline Left side bridge endurance & $18.2 \pm 3.6$ \\
\hline Standing stork & $9.2 \pm 2.9$ \\
\hline
\end{tabular}

Statistically significant positive correlation was found between core muscle endurance tests and static balance (Standing stork test). (Table:2)

Table 2: Correlation of Trunk muscle endurance and static balance

\begin{tabular}{|l|c|c|}
\hline Correlation between Standing stork test and & Pearson's Correlation Coefficient (r) & P value \\
\hline Trunk flexor endurance & 0.885 & 0.000 \\
\hline Trunk Extensor endurance & 0.760 & 0.000 \\
\hline Right Lateral flexor & 0.727 & 0.000 \\
\hline Left Lateral flexor & 0.776 & 0.000 \\
\hline
\end{tabular}

\section{DISCUSSION}

The present study was designed to find the correlation of core endurance with static balance among college student with forward head posture. Total of 25 participants with forward head posture fulfilling inclusion and exclusion criteria were recruited. Both the genders were included and among that there were female $(52 \%)$ and male (48\%) college student between the age of 18-30 years. FHP was measured by craniovertebral angle. Core endurance and static balance was assessed by core endurance test and standing stork test respectively.

The Present study found a strong positive correlation between the static balance and trunk flexor endurance $(\mathrm{r}=0.885)$, trunk extensor endurance $(\mathrm{r}=0.760)$, right side bridge $(\mathrm{r}=0.727)$ and left side bridge $(r=0.776)$, which was statistically significant $(\mathrm{p}<0.001)$. The result was supported by the study done by Barati et al which concluded that there was significant positive correlation between trunk muscle endurance and static balance in young individual. He also stated that the core is where the center of gravity is located and operates as functional units ${ }^{10}$. A study done by Suri et al to evaluate the trunk muscle attributes which are associated with balance and mobility in older adults found correlation between trunk extensor fatigue and balance ${ }^{21}$. It may be due to kyphotic posture which require increased activation of trunk extensor and leads to fatigue, therefore reduced balance was noted.

Carpes et al had concluded that there was positive effect of trunk strength and stability on low back pain, pelvis kinematic, and balance. The result of pilot study suggests the influence of trunk strength and stability on low back and pelvis pain and kinematics as well as on body balance that was in consistent with present study ${ }^{22}$.

Um JY et al conducted a study on correlation between forward head posture and body weight support distribution \& static balance ability of children in growth phase and reported that static balance was 
not affected in FHP on children. Generally center of gravity is lower in children than adults, and therefore postural deformity might have lower impact on static balance ${ }^{23}$.

A study was done by Joon-Hee Lee on effects of forward head posture on static and dynamic balance which concluded that static balance was significantly worse in FHP that was in agreement with our findings ${ }^{4}$. In FHP dynamic balance control is not affected because high activity of postural maintenance muscle was noted during dynamic balance.

Jung-ho, et al investigated the effect of FHP on postural balance in long time computer-based worker using computerized dynamic posturography and found that in FHP there was disturbance in static balance ${ }^{5}$. Due to imbalance in musculature of neck and shoulder it eventually leads neck to protrude anteriorly and to compensate this, center of gravity is displaced forward. Because of this postural deformity, it might have higher impact on static balance in young individuals which leads COG to move forward and cause stretching of ankle joint, which restricts the knee and hip movement ${ }^{24}$. It might results in difficulty to maintain the balance in static position.

Sun-myung Lee et al conducted a randomized control trial to evaluate the effectiveness of pilates treatment for forward head posture and reported that pilates is recommended as an appropriate exercise for treatment of FHP. A previous study states that in FHP standing is linked with lack of control of abdominal muscle. This inability to control of abdominal muscle aggravates the thoracic kyphosis and making it difficult to hold the head sufficiently to maintain normal eye level. As a result, FHP also has adverse effect like chronic low back pain and temporomandibular disorder ${ }^{25}$.

A study was done by Osama et al to evaluate the relationship between core endurance and back dysfunction with and without low back pain. They found that there was negative correlation between core flexor and extensor endurance with back dysfunction in $\mathrm{LBP}^{26}$. A study done by Kim $\mathrm{DH}$ et al reported altered center of gravity in chronic low back pain subjects. It states that COG is located posterior to back, leading to decreased extensor endurance as well as lordosis curve ${ }^{27}$. Lack of control in trunk musculature and altered COG results in decreased static balance

Another study was done to evaluate the correlation between trunk muscle endurance and balance in osteoarthritis knee and reported a significant correlation between trunk muscle and balance ${ }^{14}$. Hence, decreased core muscle endurance can affect the static balance in forward head posture individual. It is important to monitor any postural changes in young individuals especially FHP which can cause decrease in core muscle endurance and static balance and immediate preventive interventions to be planned.

\section{Limitations}

- Included participants were from only one tertiary care hospital. So in future to generalize this result samples can be collected from the different centers.

- Sample size was small. Thus, further confirmation of these results must be done in larger size population.

- Standing stork test for static balance was used, for better results computerized posturography is recommended.

\section{CONCLUSION}

There was significant relationship between trunk muscle endurance and static balance in FHP. There is a necessity to screen and monitor susceptible FHP among college students and to design exercise programs that improve core endurance and balance which would be safe and cost effective.

\section{Abbreviations: FHP-Forward Head \\ Posture, CVA-Craniovertebral angle, COG- Center of gravity}

Acknowledgement: None 
Conflict of Interest: There is no conflict of interest.

\section{Source of Funding: None}

Ethical Approval: Present study was approved by the Institutional Ethical Committee.

\section{REFERENCES}

1. Kendall FP, McCreary EK, Provance PG, Rodgers MM, Romani WA. Muscles: Testing and function, with posture and pain (Kendall, Muscles). 2005.

2. Winter DA. Human balance and posture control during standing and walking. Gait \& posture. 1995 Dec 1;3(4):193-214.

3. Kim MH, Yi CH, Kwon OY, Cho SH, Yoo WG. Changes in neck muscle electromyography and forward head posture of children when carrying schoolbags. Ergonomics. 2008 Jun 1;51(6):890-901.

4. Lee JH. Effects of forward head posture on static and dynamic balance control. Journal of physical therapy science. 2016;28 (1): 274-7.

5. Kang JH, Park RY, Lee SJ, Kim JY, Yoon SR, Jung KI. The effect of the forward head posture on postural balance in long time computer based worker. Annals of rehabilitation medicine. 2012 Feb;36(1):98.

6. Sawant SA, Desai MS, Kumar A. Immediate and long term effect of kinesiotaping on cervical core in forward head posture: one week follow up study. Int J Physiother Res. 2017;5(6):2521-6.

7. Worlikar AN, Shah MR. Incidence of forward head posture and associated problems in desktop users. Int. J. Health Sci. Res. 2019;9(2).

8. Son HH. The Effects of Virtual Reality Games in Posture Correction Exercise on the Posture and Balance of Patients with Forward Head Posture. Journal of the Korean Society of Physical Medicine. 2020; 15(2):11-21.

9. Susan BO. Physical Rehabilitation.

10. Barati A, Safarcherati A, Aghayari A, Azizi F, Abbasi H. Evaluation of relationship between trunk muscle endurance and static balance in male students. Asian journal of sports medicine. 2013 Dec;4(4):289.

11. Khuman PR, Kamlesh T, Surbala L. Comparison of static and dynamic balance among collegiate cricket, soccer and volleyball male players. International Journal of Health \& Allied Sciences. 2014 Jan 1;3(1):9.

12. Kranti Panta BP. A study to associate the Flamingo Test and the Stork Test in measuring static balance on healthy adults. Foot Ankle Online J. 2015;8.

13. Chevidikunnan MF, Al Saif A, Gaowgzeh RA, Mamdouh KA. Effectiveness of core muscle strengthening for improving pain and dynamic balance among female patients with patellofemoral pain syndrome. Journal of Physical Therapy Science. 2016;28(5): 1518-23.

14. Joshi SM, Sheth MS, Jayswal MM. Correlation of core muscles endurance and balance in subjects with osteoarthritis knee. International Journal of Medical Science and Public Health. 2019;8(5).

15. Salahzadeh Z, Rezaei M, Adigozali $H$, Sarbakhsh P, Hemati A, Khalilian-Ekrami N. The Evaluation of Trunk Muscle Endurance in People with And Without forward Head Posture: a Cross-Sectional Study. Muscles, Ligaments \& Tendons Journal (MLTJ). 2020 Oct 1;10(4).

16. Kahle N, Tevald MA. Core muscle strengthening's improvement of balance performance in community-dwelling older adults: A pilot study. Journal of aging and physical activity. 2014 Jan 1;22(1):65-73.

17. Waldhelm A, Li L. Endurance tests are the most reliable core stability related measurements. Journal of Sport and Health Science. 2012 Sep 1;1(2):121-8.

18. Ha SY, Sung YH. A temporary forward head posture decreases function of cervical proprioception. Journal of exercise rehabilitation. 2020 Apr;16(2):168.

19. Mamania JA, Anap DB, Tanksale D. Validity and Reliability of' on Protractor' smartphone Application For Measurement of Craniovertebral and Cranio-Horizontal Angle. International Journal of Physiotherapy. 2017 Aug 1;4 (4):207-11.

20. Rahnama L, Abdollahi I, Karimi N, Akhavan N, Arab-Khazaeli Z, Bagherzadeh M. Cervical position sense in forward head posture versus chronic neck pain: a comparative study. Journal of Clinical Physiotherapy Research. 2017;2(1):39-42.

21. Suri P, Kiely DK, Leveille SG, Frontera WR, Bean JF. Trunk muscle attributes are associated with balance and mobility in 
older adults: a pilot study. PM\&R. 2009 Oct 1;1(10):916-24.

22. Carpes FP, Reinehr FB, Mota CB. Effects of a program for trunk strength and stability on pain, low back and pelvis kinematics, and body balance: a pilot study. Journal of bodywork and movement therapies. 2008 Jan 1;12(1):22-30.

23. Um JY. Correlation between forward head posture and body weight support distribution \& static balance ability of children in growth phase. Kyoung Hee University Graduate School of Physical Education Major in Sports Science and Medicine. 2014.

24. Vernazza S, Alexandrov A, Massion J. Is the center of gravity controlled during upper trunk movements? Neuroscience letters. 1996 Mar 15;206(2-3):77-80.

25. Lee SM, Lee CH, O'Sullivan D, Jung JH, Park JJ. Clinical effectiveness of a Pilates treatment for forward head posture. Journal of physical therapy science. 2016; 28 (7): 2009-13.

26. Abdelraouf OR, Abdel-Aziem AA. The relationship between core endurance and back dysfunction in collegiate male athletes with and without nonspecific low back pain. International journal of sports physical therapy. 2016 Jun;11(3):337.

27. Kim DH, Park JK, Jeong MK. Influences of posterior-located center of gravity on lumbar extension strength, balance, and lumbar lordosis in chronic low back pain. Journal of back and musculoskeletal rehabilitation. 2014 Jan 1;27(2):231-7.

How to cite this article: Abhilash P.V, Priya S, Kheriwala MK. Correlation between static balance and core endurance among college student with forward head posture. International Journal of Science \& Healthcare Research. 2021; 6(3): 244-250. DOI: https://doi.org/ 10.52403/ijshr.20210742 